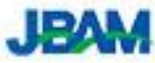

\title{
Careers Roundtable: An Exercise for Student Career Exploration and Future Development
}

\author{
Kenneth M. York, Gregory Thrasher, Nancy Savage, Jae Hyeung Kang, Michelle \\ Hammond, Caitlin A. Demsky, and Lizabeth A. Barclay \\ School of Business Administration, Oakland University
}

\section{Author Note}

Kenneth M. York (D) https://orcid.ord/ 0000-0002-0460-558X

We have no conflicts of interests to disclose.

Correspondence concerning this article should be addressed to Kenneth M. York, School of Business Administration, 275 Varner Dr., Oakland University, Rochester, MI 48309. Email: york@oakland.edu 


\title{
CAREERS ROUNDTABLE
}

\begin{abstract}
This paper describes a classroom exercise related to career development that helps students explore career paths found in their major. While we primarily focus on the Human Resource Management (HRM) major, we provide guidance for adapting the exercise to different majors as well as first year business students. First, we summarize career development literature focusing on college students. We next provide background for the development of the exercise. Our major is required to assess the curriculum as part of university-wide curricular assessment, and we will describe how this exercise grew out of that assessment. We then describe the exercise and the positive outcomes for students. In the Appendices to this paper we provide: a template illustrating how our curriculum builds across years which can be adapted to help orient students in the context of their major, complete directions for the HRM version of the exercise, and instructor teaching notes which include suggestions on how this exercise can be adapted for other majors within business schools. The exercise supports our students' concerns and university's interest in assessment and assists students as they make the transition from student life to their professional careers.
\end{abstract}

Keywords: career exploration, career planning, focus group 


\section{CAREERS ROUNDTABLE}

\section{Careers Roundtable: \\ An Exercise for Student Career Exploration and Future Development}

Career planning is important because individuals generally do not spend their careers with one employer. According to the Bureau of Labor Statistics, the median number of years that wage and salary workers have been with their current employer was 4.2 years in January 2018, and 4.1 years in January 2020 (Bureau of Labor Statistics, 2020). This means that if a typical employee works 45 years, they will have changed employers ten or more times in their career. Instead of a company career, where an employee rises through the ranks of one company, increasingly an employee has an individual career, where the employee advances in the profession, changing organizations many times. As careers become more person-specific than organization-specific, it is important that employees engage in career planning for themselves, rather than wait for the organization to plan their career for them. For example, Baker (2002) used the Armed Services Vocational Aptitude Battery "Career Exploration Program" with a nationally representative samples of high school students and found that participation in the program increased career exploration knowledge and reduced approach-approach career indecision.

When students prepare for their first career job by earning a college degree, the foundation or core courses expose students to the various functional areas of business. Through their course work, students are doing career exploration. They may find out that they were interested in accounting, but after taking a course in marketing, have found a career path that is more interesting or better matches their skill set (or both). But as this career exploration is limited to what they have learned in their courses, a more structured approach to career exploration will benefit students even after they graduate and leave the university. Wendlandt and Rochlen (2008) also highlight challenges associated with this transition to work for new college graduates.

As noted by Zikic and Hall (2009), career exploration has typically been associated with the school-to-work transition, but should be seen as a lifelong pursuit as workers deal with a rapidly changing work environment. Based on this approach, this paper presents a description of the Careers Roundtable Exercise, in which students search for information about career paths, find a related job description in O*NET, locate two graduate programs related to the career option, identify a professional association related to the career, and suggest a professional certification that supports further career development. Although the exercise was designed for Human Resources Management students, it can be easily modified for other majors. While this paper does not include an in-depth discussion of career development, we present relevant literature that supports the idea of a career exploration exercise appropriate for graduating seniors in business schools.

Some authors (Singaravelu et al., 2005) investigate family influences on career choice. While the previously cited article has to do with international students, the authors suggest that group career decision sessions can be helpful. We took this approach 


\section{CAREERS ROUNDTABLE}

in designing our roundtable exercise. Other authors (Gunkle et al., 2010) indicate that career planning is diverse and that individuals need to understand their personal interests. This is consistent with the career literature that suggests that individuals need to be selfdirected (Hirschi \& Freund, 2014). Lastly, Hirschi et al. (2018) suggest that career exploration involves collecting information about career opportunities.

As the exercise in this paper relates to Human Resource Management, we found that the Society for Human Resource Management (SHRM), the primary professional group for HR professionals, had many postings related to career development that supplement the scholarly literature. An article by Binney (2018) suggests intentionality is related to career development. This includes networking and differentiating your competencies. Another article posted on the SHRM webpage (2018), suggests certification programs and local professional groups. However, while we were aware of sources of information, we wanted to first learn about some of the career issues or concerns students had in order to better target our approach. To do so, we discuss how we investigated this important area through the formal assessment process of our major. University accreditation as well as Association to Advance Collegiate Schools of Business (AACSB, n.d.) accreditation is required at many universities, and we have found these activities useful.

\section{Assessment in Support of Curricular Change}

There is growing interest in degree outcomes in higher education (e.g., Porchea, et al., 2010). Assessment of programs increasingly includes considerations of student success post-graduation. This assessment is often a function of accreditation requirements focused on student achievement going beyond grades earned in particular classes (Barclay, et al., 2006; Bozeman, 2020; Espinoza, 2019; Gedye, 2004). Hence, the assessment process links to program objectives, and assessment data improves methods of instruction as well as course content. The goal of our particular major, Human Resources Management (HRM) is: "Emphasis is placed on developing an intensive understanding of the concepts and techniques needed to acquire, develop and utilize an organization's human resources resources....". As students often view classes as standalone experiences, we use a process-oriented approach to try to build connections for the students across the curriculum. For example, to better communicate these connections, we created a diagram that displays the courses they will take in the HRM major (required major and minor courses as well as popular electives), and their connections (see Appendix A). In the diagram we classify courses into several themes. The Introduction to HRM and the Compensation and Benefits courses focus on organizational routines; the Psychology of Creativity, New Venture Creation, and Leadership and Group Performance courses deal with organizational change; and the Organizational Behavior, Organizational Research Methods, and Motivation and Work Behavior courses link organizational routines and organizational change (the Entrepreneurship courses are included as they are part of an increasingly popular minor within the Business School). By reinforcing course relationships, we believe that students will make stronger connections between concepts when applying knowledge as an HRM professional. Additionally, to evaluate our success in meeting the goal set for our major, we collect 


\section{CAREERS ROUNDTABLE}

data in a variety of ways. While we make curricular changes based on a range of techniques, the exercise described in this paper relates to data we collected through a student focus group. Therefore, we will first describe focus groups and the data we collected.

\section{Focus Groups}

Focus groups are planned discussions to obtain perceptions about a specific issue (Krueger, 1994). Generally, we hear about focus groups in the context of marketing research; however, focus groups are an increasingly popular assessment tool (Dillon \& Barclay, 1997). The focus group allows for more in depth exploration of topics than a survey. A focus group moderator has the ability to follow up on comments made by participants to gain a better understanding of perceptions.

In our assessment process, the faculty met as a group to identify topics for the focus group discussion. In the assessment cycle that led to this exercise, we were particularly interested in topics/ideas that could help us retain students in the HRM major. Table 1 contains specific questions related to the exercise described in this paper.

These questions were of specific interest to us, as we wanted to know what types of events or information led students to our major, we wanted to know if students were interested in specialist versus generalist careers, and we wanted to know what information they thought they needed for professional career development. The responses from the focus group indicated that students, although seniors, were still unclear about the variety of career paths in HRM even though our student chapter of the Society for Human Resource Management (SHRM) and our introductory course touched on such paths. Based on the responses, we developed a Careers Roundtable exercise. The complete Careers Roundtable Exercise Assignment is contained in Appendix B and the Teaching Note for the exercise is contained in Appendix C.

\section{Table 1}

Summary Examples from Focus Group Questions and Responses Related to the Exercise

- What types of information helped you make a decision to major in HRM?

$\circ$ Job shadowing

○ Internship

- HR manager at work

$\circ$ Liked the topics and faculty

- What changes do you think could be made in [the introductory course numbers] to make the major more attractive and relevant?

- Salary negotiation skill development

- Tours

○ HR guests

Info to help decide earlier 


\section{CAREERS ROUNDTABLE}

- Knowing what you can do with an HRM career

- Have you decided on a post-graduation path (generalist/specialist)? If so what is it?

- Not sure

○ Not enough info to decide yet

- Should have guest speakers on each area

- What are your future career goals and how do you think HRM will be beneficial to achieving these goals?

$\circ$ Want salary info for negotiating

- Want to know about health and safety as a career option

- More support for next steps

- Need to know more about certification and grad programs

Note. There were additional topics discussed; however, they related class scheduling and a wider range of electives.

\section{The Careers Roundtable Exercise}

The exercise assigns specialty HRM areas to students for investigation. We did not allow students to select areas, because we wanted representation across all areas in each roundtable group. Human resource professionals can become generalists or specialists. Our students were clear on a generalist's career; however, they wanted more information on specialist areas. The areas selected for the roundtable were Recruiter, Health and Safety Professional, Training \& Development Manager, Compensation \& Benefits Professional, Employee \& Labor Relations Specialist, and Human Resource Information System Manager.

Once assigned, students were tasked with locating information about that particular career path, finding a related job description in $\mathrm{O} *$ NET, locating two graduate programs related to the career option, identifying a professional association that was related to the career, and suggesting a professional certification for that career. This exercise reinforces previous class work using O*NET.

On the day of the roundtable, students were placed in groups that provided each student with information about the assigned areas. Students presented the information about their career area and took questions from the others. At the end of the sharing session, students were asked to note on their assignment sheet which area was of most interest to them. While this last step is not necessary for a successful exercise, we thought it might provide guidance for future elective offerings as well as help the instructor tailor specific feedback to the class after the roundtable. Students reported that they appreciated learning about post-degree educational opportunities and certifications for each of the areas. Another surprise for the students was the breath of professional groups that they could join for networking opportunities. Because we have a chapter of SHRM on campus, most students know about that group and its local chapters. Some students copied down 


\section{CAREERS ROUNDTABLE}

information on other degrees and groups from those who presented. Students found a wide range of certifications available for HRM careers. For example, they located certifications in Health and Safety that were not familiar to us. In addition, a high point of the exercise was discussing graduate programs that tied into each area. In addition to traditional degrees, students also located certificate programs, which are university programs that typically consist of five or six courses. In some universities, certificate students might transition to a degree program and be able to use the certificate courses as part of the degree. Informally, several students continued the career conversation with the instructor after class.

\section{Suggestions for Conducting This Exercise with Other Majors}

A complete set of teaching notes is found in Appendix C. While our careers roundtable focused on HRM, this assignment can be adapted to other business majors. For example, accounting students may pursue graduate training through a Master of Accounting or an MBA. In addition, accounting has a range of professional certifications. Marketing students can investigate post-graduate certificate courses for development such as a digital marketing analytics option. The information reinforces information the students may have received from student organizations and university career centers. The process of finding this information also allows students to take more ownership of career development.

\section{Conclusion}

We developed this exercise in response to data we acquired through our assessment process. We believe the exercise speaks to our students' interests in career planning as well as the university's interest in the assessment process. In addition, it is an engaging way of assisting students as they make the transition from undergraduate life to professional career. 


\section{CAREERS ROUNDTABLE}

\section{References}

Association to Advance Collegiate Schools of Business (n.d.). Accreditation. https://www.aacsb.edu/accreditation.

Barclay, L.A., Markel, K.S., Schwartz, H.S., Tyler, C. L., \& York, K. M. (2006, October 27). The undergraduate HRM degree: Process challenges in a competitive environment [Conference Presentation]. Southern Industrial Relations and Human Resources Conference, Louisville, KY.

Baker, H., E. (2002). Reducing adolescent career indecision: The ASVAB career exploration program. Career Development Quarterly, 50(4), 359-370.

Binney, E. (2018, October 8). Be intentional about your career development. https://www.shrm.org/resourcesandtools/hr-topics/organizational-and-employeedevelopment/pages/be-intentional-about-your-career-development.aspx [accessed December 10, 2019].

Bozeman, E. (2020). Understanding value and motivation: Analysis of alumni from a US undergraduate business degree. Education \& Training, 63(1), 51-69.

Bureau of Labor Statistics, U.S. Department of Labor (2020, September 22). Employee tenure in 2020, USDL-20-1791. https://www.bls.gov/news.release/tenure.nr0.htm

Dillon, GJ. \& Barclay, L.A. (1997). Student focus groups as an assessment technique: A case study. The Journal of Accounting Education, 15, 457-468.

Espinoza, G. (2019). Factors that affect post-graduation satisfaction of Chilean university students. Studies in Higher Education, 44(6), 1023-1038.

Gedye, F. (2004). Students' undergraduate expectations and post-graduation experiences of the value of a degree. Journal of Geography in Higher Education, 28(3), 381396.

Gunkel, M., Schlaegel, C., Langella, I. M., \& Peluchette, J. V. (2010). Personality and career decisiveness: An international empirical comparison of business students' career planning. Personnel Review, 39(4), 503-524.

Hirschi, A., \& Freund, P. A. (2014, March). Career engagement: Investigating intraindividual predictors of weekly fluctuations in proactive career behaviors. The Career Development Quarterly, 62, 5-20.

Hirschi, A., Nagy, N., Baumeler, F., Johnston, C. S., \& Spurk, D. (2018). Assessing key predictors of career success: Development and validation of the career resources questionnaire. Journal of Career Assessment, 26(2), 338-358.

Krueger, R. A. (1994). Focus groups: A practical guide for applied research ( $\left.2^{\text {nd }} \mathrm{ed}.\right)$. Sage Publications.

O*NET (n.d.). O*NET OnLine. https://www.onetonline.org/.

Occupational Outlook Handbook (n.d.). Occupational Outlook Handbook - Bureau of Labor Statistics. https://www.bls.gov/ooh/

Porchea, S. F., Allen, J., Robbins S., \& Phelps, R. P. (2010). Predictors of long-term enrollment and degree outcomes for community college students: Integrating academic, psychosocial, socio-demographic, and situational factors. Journal of Higher Education, 81(6), 680-708.

Society for Human Resource Management (2018). Career development: What educational resources should I consider to further my HR career? https://www.shrm.org/resourcesandtools/tools-and-samples/hr- 


\section{CAREERS ROUNDTABLE}

qa/pages/resourcesstoconsidertofurthermyhrcareer.aspx [accessed December 10, 2019].

Singaravelu, H. D., White, L. J., \& Bringaze, T. B. (2005). Factors influencing international students' career choice, A comparative study. Journal of Career Development, 32(1), 46-59.

Vaughn, S., Schumm, J. S., \& Sinagub, J. (1996). Focus group interviews in education and psychology. Sage Publications.

Wendlandt, N. M., \& Rochlen, A. B. (2008). Addressing the college-to-work transition: Implications for university career counselors. Journal of Career Development, 35(2), 151-165.

Zikic, J., \& Hall, D. T. (2009). Toward a more complex view of career exploration. Career Development Quarterly, 58(2), 181-191. 


\section{Appendix A}

Degree Process Oriented Approach

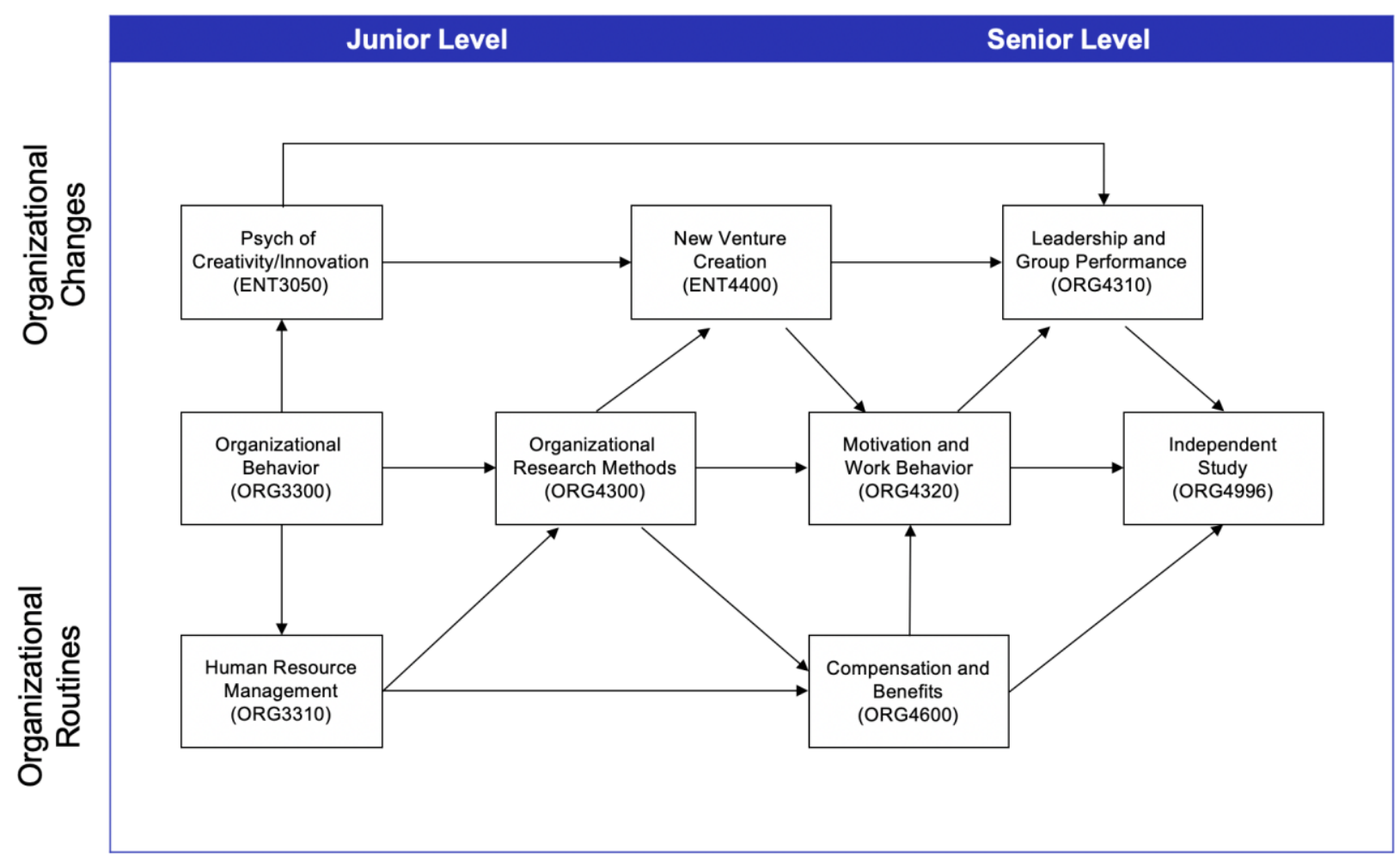




\section{Appendix B}

\section{Careers Roundtable Assignment}

Format for Bullet Document (remember to put your name at the top as you are handing this in during class):

- List the career I assigned and provide a job description with appropriate citations for a job within this career area (You should locate at least two sources of information for this, $\mathrm{O} * \mathrm{NET}$ is a good place to start).

- Find two graduate programs related to this HRM career option. List the schools and provide a link to each. Indicate which one you think is best for career development and why.

- What is the primary professional association for this career? Indicate the link to the association in your bullet document.

- Suggest an HR Certification that is related to the job. Explain why you chose it and provide a link to the certification body. If you believe that there are no appropriate certifications write a paragraph explaining why.

In class:

- You will share the information you found and answer questions from the group. At the end of sharing you will give me the bullet document.

Note. The HR Careers used for this assignment were Compensation \& Benefits, Employee \& Labor Relations, Health \& Safety, HRIS, and Training \& Development. Students were put into groups so that all of the areas could be shared within a roundtable. Options for an online class are provided in Appendix C: Teaching Note. 


\section{CAREERS ROUNDTABLE}

\section{Appendix C}

\section{Teaching Note}

This exercise was developed as a result of focus group of senior Human Resource Management students. Students were queried about aspects of career preparation in the major as well as career development issues. This assignment is most appropriate for undergraduate business students who are exploring career options within majors. While our exercise focused on the Human Resource Management major, it can easily be adapted to other majors such as Accounting, Marketing, Finance, Production and Operations Management, and Management Information Systems. In addition, if you are teaching an entry level class such as Principles of Management, you could adapt this exercise so each student is assigned a different major within business to present. This type of adaptation could lead to more informed decisions by students when selecting a major. Information collected could include a typical job, salary ranges, as well as additional education required for career progression.

\section{Learning Objectives}

1. Students learn about different specialty areas within HRM as they prepare to graduate.

2. Students learn about different graduate degree or post-bachelor certificates available in the different fields.

3. Students become familiar with the range of professional associations they can join after graduation.

\section{Faculty Preparation}

If you are the instructor conducting a careers roundtable, you first need to investigate a range of career options for your major. The Occupational Outlook Handbook (https://www.bls.gov/ooh/) and O*NET (https://www.onetonline.org/) are useful resources. In addition, many business school majors are associated with professional groups that provide information on careers. For example, in HRM, the Society for Human Resource Management has a wide range of posts on careers and certifications. Similarly, if your students are majoring in Production and Operations Management, the Association for Supply Chain Management has a number of career resources and certifications that would help you generate a list of specialty areas. By examining some of the professional groups and jobs groups within your field, you can generate different specialty areas within the major.

Once you have a range of career options, you need to assign students to areas several weeks before you conduct the roundtable. If you have five areas, each roundtable would consist of five students who each present a different option. We initially conducted this in a face-to-face class where students presented and answered questions from their peers. Prior to class, each student developed a bullet point document that touched on all items in the assignment (see Appendix B). Recently, the assignment has been adapted to an online asynchronous format where the roundtable was converted to a forum.

Here is the prompt used to open the forum in Moodle (our online platform): 


\section{CAREERS ROUNDTABLE}

- For your original post, use the career area I assigned you and provide a job description for a job in this career area (you must have a link or site from $\mathrm{O}^{*} \mathrm{NET}$ at the minimum). Find two graduate programs related to this career option. List the schools and provide a link for each.

- For your comment: Review a posting that is not from your area (I recommend that you glance through several, especially if your assigned career is not your aspirational career). Post the primary professional association for this career. Provide a link to that association and describe it. Lastly, indicate if you found any evidence (perhaps) on the association site for an HR Certification in that field.

In the online modification, the original posting contained slightly less information than the in-person bullet document; however, when commenting another a student would have to locate the remaining items but for a different career area. You can modify the prompt online and have commenters ask questions of the original poster, etc.

In both options, this assignment was graded in two parts: students earn one quarter of the number of points for being present to share. In addition, we grade the written document based on following directions and grammar because it is relatively structured and provides a starting point for class discussion. In the online version students earned a majority of their points for the original posting and one quarter of the points for the comment. 